DOI 10.37882/2223-2982.2021.07.31

\title{
ЦИФРОВИЗАЦИЯ ОБРАЗОВАНИЯ: ВЫЗОВЫ, РЕШЕНИЯ, ПЕРСПЕКТИВЫ
}

\section{DIGITALIZATION OF EDUCATION: CHALLENGES, SOLUTIONS, PROSPECTS \\ E. Strizhova \\ L. Zenina \\ T. Gerasimenko}

Summary: This article is devoted to substantiating the importance and effectiveness of the introduction of online learning in the Russian higher education system, analyzing the advantages, disadvantages, and opportunities of e-learning in the time of crisis. The authors also address the issue of the development of startups during the pandemic and crisis situations. The article includes proposals for academic institutions aimed at solving the problems associated with the introduction of online learning.

Keywords: online training, EdTech startup, M00C, human factor, Z00M.
Стрижова Екатерина Валентиновна

Стариий преподаватель, Российский экономический университет им. Г.В. Плеханова Strizhova.EV@rea.ru

Зенина Людмила Владимировна

К.n.н., доцент, Российский экономический университет им. Г.В. Плеханова

Zenina.LV@rea.ru

Герасименко Татьяна Леонидовна

Старший преподаватель, Российский экономический университет им. Г.В. Плеханова

Gerasimenko.TL@rea.ru

Аннотация: Данная статья посвящена обоснованию важности и эффективности внедрения онлайн-обучения в системе российского высшего образования, анализу преимуществ, недостатков, возможностей электронного обучения в кризисное время. Авторы также затрагивают вопрос развития стартапов во время пандемии и кризисных ситуаций. Статья включает в себя предложения для академических институтов, направленные на решение проблем, связанных с внедрением онлайн-обучения.

Ключевые слова: онлайн обучение, стартап EdTech, MOOK, человеческий фактор, ZOOM.

ных технологий, имеет ряд неоспоримых преимуществ, среди которых отсутствие проблемы географической удалённости, более низкие затраты на транспорт, проживание для обучающихся удаленных регионов и т. д. Гибкость - еще один ключевой положительный аспект онлайн-обучения: учащиеся могут самостоятельно выбирать время для изучения курсов, доступных в сети Интернет; подключаться к учебному процессу, находясь в любом месте; дипломированные специалисты получают возможность развивать новые необходимые профессиональные навыки в процессе обучения на протяжении всей своей жизни.

По словам Председателя Правительства РФ М. Мишустина дистанционное обучение и получение дополнительного образования в режиме онлайн во время пандемии коронавируса стало популярным среди людей всех возрастов, расширив возможности реализации программ непрерывного образования и повышения квалификации. Однако это не означает отказа от традиционных форм образования. «Мы говорим о разумном и оправданном использовании цифровых технологий в дополнение к традиционному обучению» [14].

Данная статья посвящена обоснованию важности и эффективности внедрения онлайн-обучения в системе 
российского высшего образования, анализу преимуществ, недостатков, возможностей электронного обучения в кризисное время, а также затрагивает вопрос развития стартапов EdTech (от английского Educational technology) во время пандемии и кризисных ситуаций, включает в себя предложения для академических институтов, направленные на решение проблем, связанных с внедрением онлайн-обучения.

Большинство терминов, связанных с электронным образованием (онлайн обучение (online learning), открытое образование (open learning), веб-обучение (web-based learning), обучение при помощи компьютеpa (computer-mediated learning), смешанное обучение (blended learning), мобильное обучение (m-learning) предполагают использование компьютера или мобильного устройства, подключенного к сети Интернет, что дает возможность учиться в любом месте, в любое время, в любом ритме, любыми средствами [8]. Онлайн-обучение можно назвать инструментом, который способен сконцентрировать учебный процесс на учащихся, сделать его более инновационным и гибким. Онлайн-обучение осуществляется в синхронной или асинхронной среде с использованием различных устройств (например, мобильных телефонов, ноутбуков и т.д.) подключенных к сети Интернет. В этих условиях студенты могут учиться и взаимодействовать с преподавателями и другими студентами, находясь в любом месте [10]. Асинхронная учебная среда создается путем использования в учебном процессе обучающих онлайн-платформ, обеспечивающих:

1. проведение видеоконференций с участием 40-50 студентов,

2. организацию дискуссий между преподавателем и студентами,

3. просмотр записанных лекций в режиме вне сети,

4. получение мгновенной обратной связи от студентов в устной форме или в форме выполненных письменных заданий.

Коронавирус заставил учебные заведения во всем мире перейти в режим онлайн и принять современные технологии обучения и преподавания. Многие университеты во всем мире полностью оцифровали свою деятельность, понимая острую необходимость данного шага в нынешней ситуации. Очень быстро произошел переход обычных классов в электронную среду обучения, то есть педагоги переориентировали весь свой педагогический подход на решение новых рыночных условий и адаптацию к меняющимся ситуациям. В это трудное время речь идет не о том, могут ли методы онлайн-обучения обеспечить качественное образование, а скорее о том, как академические учреждения смогут адаптировать онлайн-обучение в массовом порядке [7]. Об академических институтах будут судить по их темпу адаптации к изменениям за короткий период и их способности поддерживать качество обучения. В качестве примера инструментов электронной среды, которые могут быть в кратчайшие сроки внедрены и успешно использованы в учебном процессе являются следующие продукты Google:

1. Gmail,

2. Google Forms,

3. Календари,

4. G-Drive,

5. Google Hangouts,

6. Google Jam board and Drawings,

7. Google Classroom,

8. Программное обеспечение Open Board.

Эти инструменты могут быть успешно использованы в качестве альтернативы очным занятиям [6].

Очевидно, что академические институты не смогут в одночасье превратить все свои учебные программы в онлайн-ресурс. Дистанционное, масштабное и персонализированное обучение и обучение - это серьезные вызовы для традиционной системы образования. Поэтому на данном этапе повышение качества онлайн-обучения имеет решающее значение.

Применение онлайн-образовательных технологий сопряжено с рядом трудностей. Они включают в себя такие недостатки как, например, технические ошибки, возникающие при загрузке обучающего контента, проблемы с установкой программного обеспечения, проблемы входа в обучающую систему, проблемы с проигрыванием аудио и видео контента и многие другие.

Человеческий фактор также играет не последнюю роль. Иногда студенты считают онлайн-обучение скучным и неинтересным или просто не способны выделить на него свое время. Недостаток личного внимания также является огромной проблемой. Студенты хотят двухстороннего взаимодействия, что иногда бывает трудно реализовать, принимая в расчет большую численность обучающихся. Кроме того, процесс обучения не может полностью раскрыть свой потенциал, пока студенты не применяют на практике приобретенные компетенции. Зачастую онлайн-контент носит исключительно теоретический характер и не позволяет студентам эффективно практиковаться. Таким образом, основными препятствиями для широкого распространения онлайн-обучения по мнению студентов являются: посредственное содержание учебных курсов, отсутствие учебного сообщества, студенческой среды характерной для очного обучения, технические проблемы, трудности в понимании целей обучения являются [11]. Студенты недостаточно подготовлены к тому, чтобы сбалансировать свою работу, семью и социальную жизнь с учебой в онлайн-среде, не 
владея приемами тайм-менеджмента.

Использование массовых открытых онлайн-курсов (МООК) может быть сопряжено с проблемой отсутствия общепринятых стандартов работы МООК, удовлетворяющих требования университетов, обучающихся, работодателей [1].

Необходимо учитывать риски, связанные с осуществлением учебного процесса в режиме онлайн, проявляющиеся в форме хакерских атак на образовательные платформы университетов, а также в виде ограничений образовательного ресурса, не позволяющих одномоментное присутствие большого количества обучающихся.

Отечественные ученые, занимающиеся исследованием проблем смешанного обучения, отмечают, что в современных российских вузах в лучшем случае есть E-learning project manager. Обязанности остальных специалистов, таких как образовательный дизайнер, мультимедийный редактор, авторы контента, отраслевые эксперты, менеджеры по обучению, фактически возложены на преподавателя, что негативно сказывается на качестве онлайн-обучения [5].

Важно учитывать возрастные особенности профессорско-преподавательского состава. Так, нахождение в стрессовом состоянии во время технических сбоев, постоянное нахождение в условиях, не приспособленных для проведения лекционных и практических занятий может приводить к ухудшению самочувствия ряда преподавателей [2].

Вместе с тем пандемия в полной мере раскрыла человечеству потенциал, выгодную экономическую сторону онлайн - обучения. С помощью удаленного формата обучения возможно вовлекать в учебный процесс несравнимо большее количество студентов, находящихся В любой точке мира в любое удобное для них время. Все образовательные учреждения должны использовать и комбинировать различные варианты онлайн-педагогических методов чтобы попытаться использовать технологию более эффективно. Абсолютно очевидно, что мы не можем игнорировать преимущества онлайн - обучения в условиях кризисных ситуаций.

Существует ряд способов решения проблем, обозначенных выше. Например, технические трудности можно решить путем предварительной записи видеолекций, проверки и анализа их содержания перед демонстрацией. Преподаватели в вузах должны установить строгие временные ограничения для выполнения заданий и создать систему напоминаний, чтобы держать их в состоянии «боевой готовности». Необходимо делать акцент на личностный подход, используя для общения со студентами социальные сети, групповые форумы, телефонные приложения. Онлайн-курсы должны быть динамичными, креативными, интерактивными, релевантными, ориентированными на отдельных учащихся и их группы.

Задача образовательных учреждений состоит не только в том, чтобы найти новые технологии и использовать их, но и переосмыслить свои направления дополнительного образования, помогая студентам и преподавателям повышать цифровую грамотность. Преподаватели должны уделить должное внимание разработке эффективных стратегий онлайн-обучения, например, сосредоточиться на кейс-обучении и проектном обучении.

Переход к эффективному онлайн-обучению требует от заинтересованных вузов вовлечения больших объемов человеческих, финансовых, информационных ресурсов, значительных временных затрат [4]. Для успешного решения выше обозначенных проблем вузам необходимо не только скорректировать учебные планы, но и обеспечить подготовку преподавателей новой формации, способных эффективно сочетать следующие три типа компетенций, позволяющих эффективно работать в цифровой среде: преподаватель должен быть специалистом в предметной области, владеть современными образовательными технологиями, являться продвинутым пользователем современных информационных систем за счет владения необходимыми цифровыми компетенциями [3].

Рассмотрим место и роль EdTech стартапов (стартапов в сфере образовательных технологий) в развитии онлайн-обучения. Список наиболее известных стартапов EdTech на сегодняшний день включает Вујu, Adda247, Alolearning, AptusLearn, Asmakam, Board Infinity, ClassPlus, CyberVie, Egnify, Embibe, ExtraaEdge, iStar, Jungroo Learning, GlobalGyan, Lido Learning, Pesto, Vedantu, Edubrisk, ZOOM Classroom, ZOOM Business, Toppr, Unacademy, Coursera, Kahoot, Seesaw, Khan Academy, e-pathshala, GuruQ.

На наш взгляд платформа Zoom, предоставляемая стартапами EdTech, является наиболее удобной образовательной платформой, используемой в России для достижения двух важных целей нашей образовательной политики: обеспечения доступности и повышения качества. Эти платформы предлагают большое количество опций, включая видеочаты, демонстрация экрана своего компьютера (для демонстрации учебного материала и презентаций). Незаменимой опцией является для коллективных проектов является возможность использования инструмента whiteboard, являющегося аналогом школьной доски, на которой можно писать, рисовать, корректировать информацию. Доской могут пользо- 
ваться как преподаватель, так и участники конференции. Доступны также включения-выключения камеры и микрофона. Преподаватели могут использовать комбинацию аудио, видео и текста, что позволяет поддерживать максимально социальный и эмоциональный контакт со студентами. Это помогает в создании совместной и интерактивной учебной среды, где сохраняется хорошая обратная связь между студентами и преподавателем, что поддерживает у студентов интерес к учебе.

Стартапы EdTech имеют множество возможностей для радикальных преобразований практически во всех образовательных аспектах, начиная от преподавания, обучения, проведения оценки результатов, заканчивая сертификацией, присуждением степеней и т. Д. Кроме того, растущий рыночный спрос на электронное обучение - это дополнительная возможность для EdTechстартапов привнести технологические прорывы в образовательный сектор.

Однако учебным заведениям следует понимать, что внедрение и осуществление электронного обучения требует много временных и материальных затрат, поскольку необходимы существенные вложения для приобретения устройств и оборудования, их обслуживания, обучения персонала и разработки онлайн-контента. В этой связи учебным заведениям необходимо разрабатывать эффективную и действенную образовательную систему для передачи образования в онлайн-режиме.

Возможно одной из самых насущных задач в онлайнобучении является обеспечение цифрового равенства. Это очень важно, поскольку не все преподаватели и студенты имеют доступ к цифровым устройствам, сети Интернет и Wi-Fi. Отсутствие надлежащих цифровых инструментов, отсутствие подключения к Интернет или слабое подключение к Wi-Fi могут вызвать проблемы, из-за которых многие студенты могут потерять возможности обучаться. Учреждения должны предпринять усилия для обеспечения того, чтобы каждый студент и преподаватель имели доступ к необходимым ресурсам. Они также должны убедиться, что все образовательные приложения работают на смартфонах, в случае отсутствия если ноутбуков у студентов. Поэтому приоритетной задачей необходимо считать шаги по сокращению так называемого «цифрового разрыва».

В заключение следует сделать следующие выводы. Пандемия Covid-19 существенно изменила образовательные технологии. Для многих преподавателей, привыкших к проведению традиционных занятий в форме очных лекции и работе в аудитории, сложно принять назревшие изменения и инновации. Но в условиях кризиса нам необходимо принять эти изменения, чтобы адаптироваться к новой реальности.
Текущая пандемия показала, что студенты должны обладать определенными навыками, такими как умение решать проблемы управления временем, обладать критическим мышлением и способностью к адаптации к кризисной ситуации. Образовательные учреждения в свою очередь должны обеспечить технические условия, чтобы определить наличие этих навыков у своих студентов.

Пандемия, несомненно, ускорила процесс развития онлайн-обучения. Например, электронная платформа Zoom является надежным инструментом для выхода из таких внезапных ситуаций. Наше общество должно обладать высоким уровнем готовности для быстрой адаптации к различным изменениям и иметь четкие планы реагирования. Должна быть обеспечена надежность и доступность инфраструктуры информационно-коммуникационных технологий, средств обучения, цифровых учебных ресурсов в виде массовых открытых онлайнкурсов, электронных книг, электронных заметок и т.д. Обучение, содержание, мотивация, отношения и психическое здоровье - это пять важных вещей, которые педагог должен иметь в виду [9]. Такие стратегии обучения, как лекционные занятия, кейсы, дебаты, дискуссии, могут использоваться для эффективного преподавания в электронной среде. Также важна педагогическая и техническая компетентность онлайн-педагогов. Программы управления качеством и постоянное совершенствование имеют решающее значение для успеха онлайн-обучения и подготовки людей к любой кризисной ситуации.

Кризисные ситуации могут стимулировать мотивацию учебных заведений к внедрению высоко инновационных коммуникационных инструментов электронного обучения. Для эффективного обучения необходимо выбрать те технологии, которые сопряжены с минимальными затратами на закупку и техническое обслуживание, но могут при этом эффективно облегчить образовательные процессы. Прежде чем внедрять какой-либо инструмент электронного обучения, необходимо взвесить все его плюсы и минусы. Учебные институты должны проводить исследования и мониторинг для отбора наиболее подходящих технологий для различных образовательных инициатив. Необходимо внести надлежащую ясность в цель и контекст внедрения технологий, поскольку на их выбор влияют несколько факторов, таких как обеспечение безопасности, наличие и состояние лабораторий, скорость и доступ к сети Интернет, уровень цифровой грамотности участников учебного процесса и так далее. Подобные технологии уже разработаны в учебных заведениях, которым важно, чтобы ни один студент не был лишен образования из-за своего местоположения, социального класса, этнической принадлежности в кризисный период. 


\section{ЛИТЕРАТУРА}

1. Жук И.И., Панфилов А.С. Образование для цифровой экономики: онлайн-курсы как вызов университету // Медицина. Социология. Философия. Прикладные исследования. - 2020. - № 3. - С. 89 - 92.

2. Иванушкина Н.В. Исследование специфики организации онлайн-обучения в вузе // Известия Самарского научного центра Российской академии наук. Социальные, гуманитарные, медико-биологические науки. - 2021. - № 76. - Т.23. - С. 20.

3. Кузнецов Н.В. Онлайн-образование: ключевые тренды и препятствия // E-Management . - 2019. - № 1. - Т.2. - С. 23.

4. Смирнова А.С. Организация дистанционного обучения студентов в условиях пандемии // Вестник Приамурского университета им. Шолом-Алейхейма. 2020. - № 4 (41). - С. 94 - 94.

5. Семенов К.Б., Кузнецова В.Е., Иванова М.Е., Старкова Е.Н. 0 проблемах поиска путей цифровизации образовательной среды вуза //Вестник Сургутского государственного педагогического университета. - 2020. - № 4 (67). - С. 137.

6. Basilaia, G., Dgebuadze, M., Kantaria, M., \& Chokhonelidze, G. (2020). Replacing the classic learning form at universities as an immediate response to the COVID-19 virus infection in Georgia. International Journal for Research in Applied Science \& Engineering Technology, 8(III).

7. Carey, K. (2020). Is everybody ready for the big migration to online college? Actually, no. The New York Times. https://www.nytimes.com.

8. Cojocariu, V.-M., Lazar, I., Nedeff, V., Lazar, G. (2014). SWOT analysis of e-learning educational services from the perspective of their beneficiaries. Procedia-Social and Behavioral Sciences, 116, 1999-2003.

9. Martin, A. (2020). How to optimize online learning in the age of coronavirus (COVID-19): A 5-point guide for educators. https://www.researchgate.net/ publication/339944395_How_to_Optimize_Online_Learning_in_the_Age_of_Coronavirus_COVID-19_A_5-Point_Guide_for_Educators.

10. Singh, V., Thurman, A. (2019). How many ways can we define online learning? A systematic literature review of definitions of online learning (1988-2018). American Journal of Distance Education, 33(4), 289-306.

11. Song, L., Singleton, E.S., Hill, J.R., Koh, M.H. (2004). Improving online learning: Student perceptions of useful and challenging characteristics. The Internet and Higher Education, 7(1), 59-70.

12. Агранович М. Затрвты вузов на онлайн втрое превысили экономию от перехода на дистант. [Электронный ресурc]. URL: https://rg.ru/2020/11/20/zatratyvuzov-na-onlajn-vtroe-prevysili-ekonomiiu-ot-perehoda-na-distant.html.

13. Фохт Е., Голубева А. Российские студенты требуют скидки за переход на удаленку. Новузы не готовы идти на уступки. [Электронный ресурс]. URL: https:// www.bbc.com/russian/news-55072487.

14. Мишустин высказывается за формирование нормативной базы для цифровой образовательной среды. [Электронный pecypc]. URL: https://academia. interfax.ru/ru/news/articles/5002/.

с Стрижова Екатерина Валентиновна (Strizhova.EV@rea.ru), Зенина Людмила Владимировна (Zenina.LV@rea.ru), Герасименко Татьяна Леонидовна (Gerasimenko.TL@rea.ru).

Журнал «Современная наука: актуальные проблемы теории и практики» 